Gut, 1982, 23, 692-697

\title{
Effects of 24 hours of aspirin, Bufferin, paracetamol and placebo on normal human gastroduodenal mucosa
}

\author{
J W HOFTIEZER, J C O'LAUGHLIN, and K J IVEY* \\ From the Departments of Medicine, Veterans Administration Medical Center, Long Beach, California, and \\ Columbia, Missouri; and The University of California, Irvine, USA
}

SUMMARY Aspirin causes gastroduodenal erosions and/or ulcers in man when taken for prolonged periods. The effects of shorter periods of aspirin, Bufferin, or paracetamol (acetaminophen) intake as used for self-medication are unknown. In a four way, crossover, blinded endoscopic study, we compared the effects of aspirin, Bufferin, paracetamol, and placebo, two tablets four times a day for 24 hours, on the gastroduodenal mucosa of 10 normal volunteers. Both regular aspirin and Bufferin produced multiple gastric $(\mathrm{p}<0.005)$ and duodenal erosions $(\mathrm{p}<0.05$, compared with baseline and placebo studies). Paracetamol did not cause significant gastric or duodenal mucosal damage. Two subjects developed duodenal ulcer-like lesions in the course of the study. We conclude that the use of unbuffered aspirin and Bufferin, but not paracetamol, in recommended doses for one day causes significant gastroduodenal mucosal damage.

Between 20 and 30 thousand million aspirin tablets are consumed each year in the United States. ${ }^{1}$ When taken chronically in doses of eight tablets daily or more, aspirin may cause severe damage to gastroduodenal mucosa, including a $20 \%$ prevalence of gastric ulcer and $40 \%$ prevalence of gastric erosions. ${ }^{2}$ In a recent paper, Piper et al ${ }^{4}$ reported a strong positive association between heavy analgesic intake and chronic gastric ulcer. The involvement of aspirin-containing and of paracetamol-containing drugs was of similar significance. ${ }^{4}$

Microscopic changes are caused within minutes after contact of aspirin with human gastric mucosa, though this damage has largely resolved within an hour. ${ }^{5}$ Such an acute structural damage can be prevented by giving sodium bicarbonate with a neutralising capacity of $18 \mathrm{mmol}$ gastric acid ${ }^{6}$ with aspirin. Many mildly buffered aspirin preparations are on the market with the claim that they decrease the amount of damage done by aspirin. The most widely used product, Bufferin, has only $1.5 \mathrm{mmol}$ buffering capacity per tablet.

Paracetamol, a substitute for aspirin for fever reduction and pain relief, produces only minimal damage to gastric mucosal surface cells when given

\footnotetext{
* Address for correspondence: Professor Kevin J Ivey, VA Medical Center (111G), 5901 E Seventh Street, Long Beach, CA 90822 USA.

Received for publication 31 December 1981
}

acutely. ${ }^{7}$ No studies to our knowledge have been done comparing the macroscopic effects of paracetamol, aspirin, and Bufferin on gastroduodenal mucosa in man.

Most analgesics are sold on a non-prescription basis for short-term use. The aim of our study was to determine if short-term use of unbuffered aspirin caused significant endoscopically visible, macroscopic damage to gastroduodenal mucosa and if less damage is caused by commonly-used alternatives, Bufferin and paracetamol, given over 24 hours to normal volunteers.

\section{Methods}

\section{SUBJECTS}

We studied 10 healthy volunteers aged 20-37 years. Each had a normal history and physical examination, gastroduodenoscopy, and laboratory screen consisting of a 12/60 test, electrolytes, complete blood count with differential, prothrombin time, activated partial thromboplastin time, and urinalysis before inclusion into the study. Each abstained from alcohol and other medications during the course of the study.

\section{PLAN OF STUDY}

The study, approved by the institutional human use committee, was a single blind (investigator) four- 
way crossover study; each subject was tested on each drug. Drugs were regular aspirin (Bayer), Bufferin, paracetamol (Tylenol), all $325 \mathrm{mg}$ tablets, and a placebo. Subjects were not told which drug they were on but theoretically could identify tablets by comparison with commercially available similar brand tablets. A period of two weeks separated each drug challenge and the order in which the drugs were allotted was determined by a random distribution table. The drug challenge consisted of taking two tablets by mouth, with each of three meals and at 10:00 pm the evening before the study for a total of eight tablets or $2.6 \mathrm{~g}$ of medication. Fasting subjects reported to the gastroenterology laboratory at 8:00 am the next morning, where they were then given two additional tablets of the study drug to take with $100 \mathrm{ml}$ of tap water. A blood sample was drawn one-half hour later for determining levels of serum salicylate and paracetamol, and the subjects then underwent gastroduodenoscopy. After gastroscopy, each subject had additional blood drawn for a 12/60 test, complete blood count with differential, prothrombin time, and activated partial thromboplastin time.

\section{TECHNICAL ASPECTS}

The history was taken on a standardised form which covered an extensive range of upper gastrointestinal symptoms. A positive symptom history during each drug challenge period was given a grade of ' 1 ' and negative symptom history given a grade of ' 0 ', for the purposes of statistical analysis.

The gastroduodenoscopy was performed by two gastrenterology fellows, and observed by a gastroenterology faculty member through a teaching attachment, using an Olympus GIF P-2, paediatric endoscope (Olympus Corporation of America, New Hyde Park, New York). No endoscopist was aware which drug was being taken. The number of erosive lesions was tabulated separately for the stomach and duodenum. Erythema was graded according to Table 1. Each area was graded before passing the endoscope through the area, to prevent trauma artefact. Erosive lesions and erythema grades for each area were analysed statistically separately for each anatomical area.

Table 1 Grade scale for gastroduodenal erythema

\begin{tabular}{ll}
\hline $\begin{array}{l}\text { Areas of erythema } \\
\text { (no.) }\end{array}$ & Grade \\
\hline 1 & 1 \\
$2-5$ & 2 \\
$6-20$ & 3 \\
Diffuse & 4 \\
\hline
\end{tabular}

The serum was frozen and stored until the end of the study when salicylate and paracetamol levels were determined in a single run. Serum salicylates were measured by a modification of the spectrofluorometric procedure of Bender. ${ }^{8}$ Paracetamol levels were determined by visual light spectroscopy. ${ }^{9}$

\section{STATISTICS}

All data, tabulated and graded as described above, were analysed by the use of the Wilcoxon signed rank test for paired populations.

\section{Results}

\section{ENDOSCOPIC FINDINGS}

\section{Gastric erosions}

Regular aspirin No subject had erosions at the screening endoscopy. Nine of 10 subjects developed multiple antral erosions with regular aspirin ( $p<0.005$ compared with baseline, placebo, and paracetamol studies). The one subject who did not have antral erosions had a J-shaped stomach with a high non-dependent antrum. Five subjects also had erosions in the body of the stomach. In individual subjects, the total number of gastric erosions varied from five to 50 (Table 2). Most erosions were small, from $1-3 \mathrm{~mm}$ in size. Occasional erosions were larger than $1 \mathrm{~cm}$ in diameter, the largest lesion being a 'T'-shaped erosion with dimensions of $4 \mathrm{~cm}$ by 2 $\mathrm{cm}$ by $0.5 \mathrm{~cm}$ wide. Evidence for recent bleeding, consisting of petechiae, submucosal haemorrhages, or blood clots in the base of an erosion was found in nine subjects in the body, antrum, or both.

Bufferin Nine subjects developed multiple antral erosions while taking Bufferin for 24 hours ( $p<0.005$ compared with baseline, placebo, and paracetamol studies). Two subjects also had erosions in the body. Evidence of recent bleeding was found in seven subjects. Differences between regular aspirin and Bufferin studies were not significant.

Paracetamol and placebo One subject had two superficial antral erosions with otherwise normal mucosa after taking paracetamol; no subject had erosions after the placebo. No statistical significance existed between the results of the baseline, placebo, and paracetamol studies.

\section{Duodenal erosions}

Regular aspirin Six subjects had duodenal erosions with regular aspirin, number of lesions varying from one to 10 (Table 2 ). These results were significantly greater than the baseline and placebo studies at the $\mathrm{p}<0.05$ level.

Bufferin Four subjects developed duodenal 
Table 2 Number of erosive lesions seen at endoscopy

\begin{tabular}{|c|c|c|c|c|c|c|c|c|c|c|}
\hline \multirow{2}{*}{$\begin{array}{l}\text { Subject } \\
\text { no. }\end{array}$} & \multicolumn{2}{|c|}{ Baseline } & \multicolumn{2}{|c|}{ Aspirin } & \multicolumn{2}{|c|}{ Bufferin } & \multicolumn{2}{|c|}{ Placebo } & \multicolumn{2}{|c|}{ Paracetamol } \\
\hline & $G$ & $D$ & $G$ & $D$ & $G$ & $D$ & $G$ & $D$ & $G$ & $D$ \\
\hline 1 & 0 & 0 & 0 & 0 & 0 & 0 & 0 & 0 & 0 & 0 \\
\hline 2 & 0 & 0 & 15 & 2 & 3 & 0 & 0 & 0 & 0 & 0 \\
\hline 3 & 0 & 0 & 15 & 10 & 10 & 15 & 0 & 2 & 0 & 2 \\
\hline 4 & 0 & 0 & $>50$ & 0 & 15 & 0 & 0 & 0 & 0 & 0 \\
\hline 5 & 0 & 0 & 6 & 6 & 2 & 2 & 0 & 0 & 0 & 0 \\
\hline 6 & 0 & 0 & 5 & 7 & 10 & 6 & 0 & 0 & 0 & 0 \\
\hline 7 & 0 & 0 & 5 & 0 & 3 & 0 & 0 & 0 & 2 & 2 \\
\hline 8 & 0 & 0 & 10 & 1 & 15 & 10 & 0 & 8 & 0 & 6 \\
\hline 9 & 0 & 0 & 10 & 8 & 5 & 0 & 0 & 0 & 0 & 0 \\
\hline 10 & 0 & 0 & 6 & 0 & 8 & 0 & 0 & 0 & 0 & 0 \\
\hline
\end{tabular}

G: gastric. D: duodenal.

erosions after taking Bufferin, the number of lesions varying from two to $15(\mathrm{p}<0.05$ compared with baseline and placebo studies). In two subjects some duodenal lesions appeared to 'carry over' into the subsequent placebo and paracetamol study periods (Table 3). Subject 3 after Bufferin had multiple (15) duodenal erosions; two of these appeared to be deeper than the others and resembled acute peptic ulcers. Because of the severity of these erosions and symptoms of dyspepsia relieved by antacids, a second endoscopy was carried out on this subject one week later - that is, one week before the next phase - the placebo treatment - of the study. The two lesions resembling acute ulcers were still present while the other duodenal and gastric erosions as well as gastric and duodenal erythema had resolved. As symptoms largely disappeared in the second week, it was decided not to break the code and to continue the study. During subsequent treatments with a placebo and paracetamol these two lesions were present at the same site, although she was asymptomatic. When placed on aspirin, she developed burning epigastric pain requiring antacid therapy again in order to complete the study. After the study she received cimetidine and antacids and her duodenum and stomach were normal two weeks later by endoscopy. Subject 8 had his aspirin study first, followed two weeks later by the Bufferin study. He had multiple (10) duodenal erosions after Bufferin intake. Many of these persisted during the placebo and paracetamol phases of the study and in the absence of gastric erosions (Table 3). Because of this, a second endoscopy was carried out two weeks after the completion of the study - that is, six weeks after he last took acetylsalicylic acid (Bufferin). Three ulcers, each $0.5 \mathrm{~cm}$ in diameter, were present in the absence of any other gastric or duodenal erosions or erythema. These were in the same area as the previous 'erosions'. He was then placed on cimetidine and a second endoscopy carried out six weeks later. Three large erosions were still present. He was asymptomatic throughout.

Table 3 Chronological sequence of drugs for two subjects who developed persistent duodenal ulcers

\begin{tabular}{|c|c|c|c|c|c|c|c|c|c|c|}
\hline & \multicolumn{10}{|c|}{ Order in which drugs were taken } \\
\hline & \multicolumn{2}{|c|}{ Baseline } & \multicolumn{2}{|c|}{ Bufferin } & \multicolumn{2}{|c|}{ Placebo } & \multicolumn{2}{|c|}{ Paracetamol } & \multicolumn{2}{|c|}{ Aspirin } \\
\hline & $G$ & $D$ & $G$ & $D$ & $G$ & $D$ & $G$ & $D$ & $G$ & $D$ \\
\hline \multirow{4}{*}{$\begin{array}{l}\text { Subject } 3 \\
\text { Erosions } \\
\text { Erythema }\end{array}$} & & & & & & & & & & \\
\hline & 0 & 0 & 10 & 15 & 0 & 2 & 0 & 2 & 15 & 10 \\
\hline & 0 & 0 & 4 & 2 & 0 & 0 & 0 & 0 & 4 & 2 \\
\hline & & & \multicolumn{2}{|c|}{ Aspirin } & \multicolumn{2}{|c|}{ Bufferin } & \multicolumn{2}{|c|}{ Placebo } & \multicolumn{2}{|c|}{ Paracetamol } \\
\hline \multicolumn{11}{|l|}{ Subject 8} \\
\hline Erosions & 0 & 0 & 10 & 1 & 15 & 10 & 0 & 8 & 0 & 6 \\
\hline Erythema & 0 & 0 & 4 & 4 & 3 & 4 & 2 & 3 & 0 & 6 \\
\hline
\end{tabular}

G: gastric. D: duodenal. 
Paracetamol and placebo Three subjects had duodenal erosions after completing the paracetamol leg of the study ( $>>0.05)$ and two of these three also had erosions after the placebo leg $(p>0 \cdot 05)$. Both of these subjects had multiple duodenal 'erosions' on Bufferin, which appeared to persist through the placebo and paracetamol studies (Table 3 ).

\section{Gastric erythema}

Varying degrees of erythema were found in two subjects in the baseline study. All 10 subjects developed gastric erythema after taking regular aspirin $(\mathrm{p}<0.025$ compared with baseline, placebo, and paracetamol studies). Nine subjects developed erythema after taking Bufferin ( $p<0.025$ compared with baseline). While nine subjects showed erythema after placebo ( $\mathrm{p}<0.05 v s$ baseline), as did six subjects after paracetamol: marked erythema (grades 3 or 4) was characteristic only of aspirin and Bufferin studies (Table 4).

\section{Duodenal erythema}

No subject had duodenal erythema in the baseline study. Eight subjects had duodenal erythema after taking regular aspirin $(\mathrm{p}<0.025$ compared with baseline, placebo, and paracetamol), and five subjects had duodenal erythema after taking Bufferin $(\mathrm{p}<0.025$ compared with baseline). Regular aspirin caused more duodenal erythema than Bufferin $(\mathrm{p}<0 \cdot 05$, Table 3$)$.

\section{Symptoms}

No subject had symptoms at the beginning of the study. Four subjects developed symptoms taking Bufferin ( $p<0.05$ compared with baseline, placebo, and paracetamol) and one subject also developed burning epigastric pain while taking regular aspirin.
No subject had symptoms while taking placebo or paracetamol. Bufferin caused symptoms of nausea in one, mild epigastric fullness and nausea in another, and burning epigastric pains after tablet ingestion in two. Two with symptoms had epigastric tenderness compared with none of the asymptomatic subjects.

\section{Laboratory data}

No subject had abnormal blood values of any test used before or during the study. In particular, the haemoglobin, prothrombin time, bilirubin, and liver enzymes (SGOT, SGPT, alkaline phosphatase) were normal.

\section{Serum drug level}

Mean serum salicylates \pm SE was $0.59 \pm 0.07 \mathrm{mmol} / \mathrm{l}$ $(8 \cdot 2 \pm 0.9 \mathrm{mg} \%)$ with regular aspirin and $0.61 \pm 0 \cdot 04$ $\mathrm{mmol} / \mathrm{l}(8.4 \pm 0.6 \mathrm{mg} \%)$ with Bufferin. Mean serum paracetamol level was $5.06 \pm 0.94 \mathrm{mmol} / 1$ (70 \pm 13 $\mathrm{mg} \%)$.

\section{Discussion}

In this study, $90 \%$ of subjects taking aspirin or Bufferin in recommended doses for one day developed extensive gastroduodenal mucosal erosions and erythema. While adequate buffering of gastric acid prevents acute mucosal damage from aspirin, ${ }^{6}$ the small amount of buffer in Bufferin is not enough to protect. Of particular concern was the severity and persistence of duodenal 'erosions' or ulcers after the aspirin and/or Bufferin phases of the study in two subjects. We have previously shown that aspirin can damage human small intestinal mucosa if the $\mathrm{pH}$ is around the $\mathrm{pKa}$ value of aspirin of $3 \cdot 5 .^{10}$ The $\mathrm{pH}$ of the normal duodenum is often

Table 4 Erythema grades given at endoscopy

\begin{tabular}{|c|c|c|c|c|c|c|c|c|c|c|}
\hline \multirow{3}{*}{$\begin{array}{l}\text { Subject } \\
\text { no. }\end{array}$} & \multicolumn{10}{|c|}{ Erythema grades with: } \\
\hline & \multicolumn{2}{|c|}{ Baseline } & \multicolumn{2}{|c|}{ Aspirin } & \multicolumn{2}{|c|}{ Bufferin } & \multicolumn{2}{|c|}{ Placebo } & \multicolumn{2}{|c|}{ Paracetamol } \\
\hline & $G$ & $D$ & $G$ & $D$ & $G$ & $D$ & $G$ & $D$ & $G$ & $D$ \\
\hline 1 & 0 & 0 & 4 & 2 & 0 & 0 & 2 & 2 & 2 & 0 \\
\hline 2 & 0 & 0 & 3 & 2 & 3 & 3 & 2 & 0 & 2 & 0 \\
\hline 3 & 0 & 0 & 4 & 2 & 4 & 2 & 0 & 0 & 0 & 0 \\
\hline 4 & 2 & 0 & 4 & 0 & 2 & 0 & 2 & 0 & 2 & 0 \\
\hline 5 & 0 & 0 & 3 & 2 & 2 & 0 & 1 & 0 & 0 & 0 \\
\hline 6 & 0 & 0 & 4 & 3 & 4 & 3 & 2 & 0 & 2 & 0 \\
\hline 7 & 3 & 0 & 2 & 2 & 3 & 0 & 2 & 0 & 2 & 2 \\
\hline 8 & 0 & 0 & 4 & 4 & 3 & 4 & 2 & 3 & 0 & 2 \\
\hline 9 & 0 & 0 & 4 & 4 & 2 & 1 & 2 & 2 & 1 & 1 \\
\hline 10 & 0 & 0 & 2 & 0 & 3 & 0 & 2 & 0 & 0 & 0 \\
\hline
\end{tabular}

G: gastric. D: duodenum. 
between $\mathrm{pH} 2$ and $4 .{ }^{11} 12$ When this is so, conditions are right for aspirin to produce damage. The formation of severe persistent duodenal lesions resembling acute peptic ulceration after 24 hours' exposure to Bufferin alone or Bufferin after aspirin two weeks previously is a new finding for drug damage. In an endoscopic study of patients after a major burn, acute gastric (86\%) and duodenal (67\%) erosions developed within 24 to 72 hours, to be followed by gastric ulcer $(22 \%)$ or duodenal ulcer $(28 \%)$ by 72 hours or later. ${ }^{13}$ In two cases, duodenal ulcer was observed to evolve from an erosive duodenitis. In one of our two patients with duodenal ulcer, the ulcerations appeared to evolve from multiple erosions, while, in the other subject, two deeper lesions resembling acute ulcers were present 24 hours after the first exposure to the aspirincontaining drug (Bufferin). Lanza et al ${ }^{14}{ }^{15}$ reported the development of frank gastric ulceration in two volunteers given naprosỳn $(500 \mathrm{mg} /$ day $)$ or indomethacin $(100 \mathrm{mg} /$ day $)$ for one week. Other subjects given the same or larger doses of both drugs did not develop 'invasive' ulceration. Our study, indicating that deeper ulcers can develop in some subjects and not in others, clearly warrants further study. In a previous study of patients with rheumatic diseases taking chronic aspirin therapy, a prevalence rate of $4 \%$ duodenal ulcer and $13 \%$ duodenal erosions was found. ${ }^{3}$ Attention to aspirin, including Bufferin, intake, particularly brief and/or intermittent exposures over a 24-hour period, must be paid in the history of patients in whom duodenal ulcers or erosions are detected.

Our results do not support a causal relationship for the recently reported significant epidemiological association between chronic intake of paracetamolcontaining drugs and chronic gastric ulcer. ${ }^{4}$ On the other hand, our finding that aspirin-containing drugs cause gastric erosions in nearly all subjects are quite consistent with a causal relationship for the significant association of chronic aspirin intake and chronic gastric ulcer. ${ }^{4}$ In our studies, gastric mucosal damage was not significantly increased after paracetamol intake compared with baseline or placebo studies. Piper $e t a l^{4}$ did not find a significant association between heavy analgesic intake with either aspirin or paracetamol and chronic duodenal ulcer. Yet our study and earlier studies ${ }^{16}$ indicate that 24 hours' or two weeks' administration of regular aspirin produces significant duodenal damage. On the other hand, acute paracetamol did not produce statistically significant duodenal damage. The impression we gained from the current study was that in the few subjects who had duodenal erosions after paracetamol (and placebo) administration, this was mostly a 'carry over' effect from previous aspirin or Bufferin administration, although the design of our study does not allow us to say this with absolute certainty.

In conclusion, aspirin or Bufferin in recommended doses causes significant gastroduodenal mucosal erosive lesions in the majority of normal subjects after 24 hours. Paracetamol does not cause significant gastric or duodenal mucosal injury. The small amount of buffer in Bufferin does not significantly decrease mucosal damage. In two subjects, lesions indistinguishable from duodenal ulcer disease persisted at the end of the study. The role of brief or intermittent periods of ingestion of analgesics in the pathogenesis of duodenal ulcer or erosions requires further careful evaluation, but it may be more important than has previously been recognised.

This work was supported in part by the Medical Research Service of the Veterans Administration, and CRC NIH Grant No. RR00287-12. The assistance of $\mathrm{Mr}$ John Hewett, biostatistician, is gratefully acknowledged.

\section{References}

1 Moyersolm M, Thow MS, Kastebauder HB, Rowland M. Aspirin. J Am Pharm Assoc 1977; 17: 107-12.

2 Silvoso GR, Ivey KJ, Butt JH et al. Incidence of gastric lesions in patients with rheumatic disease on chronic aspirin therapy. Ann Intern Med 1979; 91: 517-20.

3 Lockard OO, Ivey KJ, Butt JH et al. The incidence of duodenal lesions in patients with rheumatic diseases on chronic aspirin therapy. Gastrointestinal Endosc 1980; 26: 5-7.

4 Piper DW, McIntosh JH, Ariotti DE, Fenton BH, MacLennan R. Analgesic ingestion and chronic peptic ulcer. Gastroenterology 1981; 80: 427-32.

5 Baskin WN, Ivey KJ, Krause W, Jeffery E, Gemmell RT. Aspirin induced ultrastructural changes in human gastric mucosa. Ann Intern Med 1976; 85: 294-303.

6 Bowen B, Krause W, Ivey KJ. Effect of sodium bicarbonate on aspirin induced damage and potential difference. Br Med J 1977; 2: 1052-55.

7 Ivey KJ, Silvoso GR, Krause W. Effect of paracetamol (acetaminophen) on gastric mucosa. Br Med J 1977; 1: 1586-8.

8 Bender GT. Clinical instrumentation: a laboratory manual based on clinical chemistry. Philadelphia, PA: Saunders, 1972: 62-4.

9 Thomas BH, Coldwell BB. Estimation of phenacetin and paracetamol in plasma and urine by gas liquid chromatography. J Pharm Pharmacol 1972; 24: 243-5.

10 Ivey KJ, Baskin WN, Krause WJ et al. Effect of aspirin 
and acid on human jejunal mucosa. An ultrastructural study. Gastroenterology 1965; 76: 50-6.

11 Andersson S, Grossman MI. Profile of $\mathrm{pH}$, pressure, and potential difference at gastroduodenal junction in man. Gastroenterology 1965; 49: 364-71.

12 Archambault AP, Rovelstad RA, Carlson HC. In situ $\mathrm{pH}$ of duodenal bulb contents in normal and duodenal ulcer patients. Gastroenterology 1967; 52: 940-7.

13 Czasa AJ, McAlhaney JC, Pruitt BA. Acute gastroduodenal disease after thermal injury. An endoscopic evaluation of incidence and natural history. $N$ Engl $J$ Med 1974; 291: 925-9.

14 Lanza FL, Royer GL, Nelson RS, Chen TT, Seckman
CE, Rack MF. The effects of motrin, indocin, aspirin, naprosyn and placebo on the gastric mucosa of normal volunteers. A gastroscopic study. Gastrointest Endosc 1978; 24: 203.

15 Lanza FL, Royer GL, Nelson RS, Chen TT, Seckman CE, Rack MF. The effects of motrin, indocin, aspirin, naprosyn and placebo on the gastric mucosa of normal volunteers. A gastroscopic and photographic study. Dig Dis Sci 1979; 24: 823-8.

16 Hoftiezer JH, Silvoso GR, Burks M, Ivey KJ. Comparison of the effects of regular and enteric coated aspirin on gastro-duodenal mucosa of man. Lancet 1980; 2: 609-12. 